so far issued, one contains general information regarding the work of the Association and others deal with the distribution of fresh food, human wastes, their collection and disposal, and a summary of existing methods of disposal. The first of these outlines a system. of fresh-food production and distribution, assuming a network of 'control farms' and 'fresh food centres'. Those on human wastes summarize suggestions as to how such wastes can be used to maintain soil fertility, and give a technical analysis of present systems of disposal. The Association is also engaged on the preparation of a series of maps, designed to present existing statistical and other information on various problems in visual form. It is also studying the problems of a service to promote positive health and the lay-out of a "health centre', standards governing housing density, prefabrication possibilities in housing construction, and the marketing of goods in relation to planning.

\section{Scientific Data in Glass Technology}

In his presidential address to the Society of Glass Technology, delivered on April 14, Dr. S. English discussed "The Cornmercial Use of Scientific Data". After a brief review of the rapid development of the science of glass technology during the past twentyfive years, and the importance of the results obtained in their application to manufacturing processes, the problems of illuminating glassware of the diffusing type were considered in detail. Three essential requirements of such glassware are that it should be (1) practicable from the manufacturing point of view, (2) technically correct from the illuminating point of view, (3) artistically correct. The problem of glare was emphasized in relation to the adaptability of the human eye to an enormous range of illumination intensities from 2,000 to 4,000 ft.-candles on a bright summer day to $0 \cdot 002-\mathrm{ft}$. candles for A.R.P. lighting. Diffusing glass envelopes reduce the glare and increase the detail comprehended by the eye by removing the intensely bright source from direct vision.

The properties of completely diffusing opal glasses in conjunction with metal filament lamps were then described. In general, the percentage transmission of opal glasses is always higher for directed light than for diffused light $(2.5$ per cent increase). The proportion absorbed is always less for directed than for diffused light, by approximately 1-5 per cent, and the proportion reflected is usually less for directed than for diffused light. Examples were given of the use of physical data for the predetermination of the performance of a lighting fitting made in flat opal glass plate, illuminated on one side by a single electric filament lamp, with and without a second plate behind the lamp to serve as reflector, and of a complete opal sphere enclosing the lamp. The efficiency of an opal sphere as a lighting unit depends on the glass, which must be a perfect sphere of uniform thickness, with no neck opening, and giving perfect diffusion of transmitted and reflected light; and on the lamp, which must give a uniform light distribution. The view was expressed that the British illuminating glassware industry should endeavour to provide the whole of the post-war requirements of Great Britain in this field.

\section{Jig Borer Microscope}

THE recent introduction of the "Watts" jig borer microscope provides a valuable optical accessory for use with high-precision machine tools such as jig borers, and tool-room milling machines. Its purpose is to enable the axis of the machine to be accurately located in relation to a datum mark on the workpiece. In construction, it consists of a high-power microscope the optical path of which is bent so that the user can conveniently inspect the work from one side when the instrument is set up in the spindle of the machine. The microscope is mounted on a taper shank-No. 4 morse taper is used in the standard model but any of the usual tapers can be suppliedand the shank is inserted in the spindle. In this position the objective axis of the microscope coincides with that of the boring spindle, which the operator is thus enabled to bring within an accuracy of 0.00005 in. to the desired position.

The optical system is so arranged that the intersecting points of the graticule lines when viewed through the eye-piece, which is of the screw-focusing type, are superimposed on the point where the projected axis of the spindle falls on the work-piece. The microscope, which has a power of $\times 45$, can therefore be used $(a)$ for setting the spindle over a small punch mark, $(b)$ for setting the spindle over a line marked on the work-piece, or (c) with the aid of a reference square, for setting the spindle in the plane of any desired surface of the work-piece. The graticule or cross-lines seen in the eye-piece of the microscope are centred relative to the taper shank, but in order to compensate for a small degree of spindle run-out, should this be experienced, provision is made for the adjustment of the diaphragm to enable the cross-lines to be re-set. As the spindle is free to rotate, the instrument has the merit of being self-checking by turning it through an angle of $180^{\circ}$, and a rotatable reflector is arranged so that the light from any convenient lamp can be brought to bear on the job. The instrument is thus well designed to simplify what is a fundamentally difficult setting in precision machine work. The makers are Messrs. E. R. Watts and Son, Ltd., 123 Camberwell Road, London, S.E.5, from whom further details can be obtained.

\section{Phenology of 1941}

Repeating its admirable promptness of last year, the Royal Meteorological Society has issued its fifty-first annual phenological report, for the year 1941, under the editorship of Major H. C. Gunther, although it is somewhat abridged from its pre-war size. It is interesting because of the late spring and the amends of a belated summer, with a remarkably green autumn countryside and an unusually late defoliation of trees, although autumn colours were not much in evidence. The migrant birds arrived punctually in the south but late in the north; there were average numbers of the immigrant painted lady and red admiral butterflies and of the silver $\mathrm{Y}$ moth, while clouded yellow butterflies were reported from many parts of the country, including the north. Observations on the magpie moth and the meadow brown butterfly in relation to the rise in temperature for the June-July warm spell which followed the cold late spring illustrated how quickly certain insects may respond to the influence of a favourable spell following adverse conditions. Observations on the dog-rose furnished clear-cut evidence of the preponderating importance of the weather of the moment as compared with any latent tendencies due to a previous season, for in 1941 the flowering dates for the south-east were not less than 16 days later than those for 1940 , when the south-east dates were 